\title{
Küçükbaş Hayvan Süt Sağım Makinalarında Nabız Karakteristiklerinin PIC Yardımıyla Kontrolü
}

\author{
Recai GÜRHAN ${ }^{1} \quad$ Mustafa ÇETIN ${ }^{\dagger}$
}

Geliş Tarihi : 09.04.2002

\begin{abstract}
Özet: Bu çalışmada küçükbaş hayvanların sag̃ım makinalarında kulianılan elektronik nabız aygıtlarına uygun merkezi bir kontrol unitesi geliştirilmiştir. Merkezi kontrol anitesinin otomasyonunun gerçekleştirilmesinde PIC olarak adlandirilan programlanabilir bir kontrol aygıtından yararlanilmıştır. Yapılan denemeler sonucunda otomasyon sisteminin sag̉ım için gerekli koşullan yüksek bir kararlılıkla sağladığı belirlenmiştir.
\end{abstract}

Anahtar Kelimeler: kúçükbaş sağımı, elektronik nabız aygıtı, otomasyon, PIC

\section{Control of Pulsation Characteristics in Small Ruminant's Milking Machines Aided with PIC}

\begin{abstract}
In this study, a control unit was developed for electronic pulsator using with milking machine for small ruminant. Central control unit was made by PIC (Peripheral Interface Controller). According to the test result, it is determined that all the parameter values in milking are satisfied in high stability by the autornation system.
\end{abstract}

Key Words : small ruminant milking, electronic pulsator, automation, PIC

\section{Giriş}

Dengeli beslenmenin temel koşullarindan birisi de hayvansal proteinlerin yeterli düzeyde tüketilmesi olmaktadır, Insanların dengeli beslenebilmesi için günlük protein ihtiyacinın en az \%35-40'inın hayvansal ürünlerden karșılanması gerekmektedir. Bunun karşılanmasında sütün önemi öncelikli yer almaktadır (Anonim 2001a).

Dünya süt üretimi ağırlıklı olarak sığır, koyun ve keçi; türlerinden sağlanmaktadır. Ülkelerin; doğal, ekonomik, sosyal ve tarımsal yapısı ile gelenekleri, sut üretiminde bu türlere verilen öncelik ve ağırlığı belirlenmektedir. Türkiye'nin doğal ve ekonomik koșulları ile tarımsal yapısı ve gelenekleri koyun ve keçi yetiştiriciliğinin yaygın olarak yapılmasına ve tarım içerisinde önemli bir yer tutmasına uygun bir ortam oluşturmaktadir. Bunun sonucu olarak Türkiye'nin süt üretiminin $\% 12$ 'si koyun ve keçiden sağlanmaktadır (Anonim 2001a).

Dünya koyun ve keçi varlığının ülkelere ve aymı ülkenin çeşitli bölgelerine göre dağilımı farklilik göstermektedir. Dünya koyun ve keçi varlığı; bunların çeşitli ülkelere göre dağılımı ve ülkelerin dünya koyun ve keçi varlığındaki payları Çizelge $1^{\prime}$ de verilmektedir. Gelişmiş ülkelerde tarımsal üretim içerisinde hayvansal üretimin payı \%60-70 iken Türkiye'de bu oranın artmadığı, yıllardır \%30'lar düzeyinde seyrettiği billinmektedir. Hayvansal üretimin tarımsal üretim içerisindeki payının gerilemesinin en önemli nedeni, bitkisel üretime sağlanan katkının hayvansal üretimde gerçekleştirilememesi olmaktadır (Anonim 2001a) Ülkelerin hayvan varlıklarının fazla olması ekonomiye aynı ölçüde katkı sağlayacağı anlamina gelmemektedir. Önemli olan mevcut hayvanlardan elde edilen ürünlerin miktarı ve niteliğl olmaktadır. Ağırlıklı olarak düșük verimli yerli ırklarla, ekstansif tarzda yürütōlen küçükbaş hayvan yetiştiriciliğinin Türkiye ekonomisine katkısı bu nedenle sayısal varlığına uygun olmamaktadır. Ayrica yıllar itibariyle küçükbaș hayvan varlığımızdaki düşüşe paralel olarak bu hayvaniardan elde edilen süt miktarında da bir azalma olmaktadır. Aslında sözü edilen ürünlere olan intiyaç, nüfus artışına da paralel olarak bir artıș göstermektedir (Anonim 200\%). Ölkemizde sağılan küçükbaș hayvan sayıları ve bu hayvanlardan elde edilen süt üretimi Çizelge 2'de gösterilmektedir (Anonim 1998).

Ülkemizde süt üretimine katkıda bulunan türler içerisinde sığırın öneminin gün geçtikçe artığı bilinmektedir. Ama bu husus küçükbaş hayvan süt veriminin önemli olmadığı şeklinde de değeriendirilmemelidir. Türkiye'de toplam süt üretimi ve bunda çeşitli türlerin payları incelendiğinde sığırın payının dünya ortalaması olan $\% 86$ değerinin üzerine çıkarak 1999 yılında \%88,92 ye çıktığı görülmektedir. Sığırın payındaki bu artış, sığır sütü üretimindeki artıştan deği giderek azalan küçükbaş hayvan sutü üretiminden kaynaklanmaktadır. Bu durum Türkiye hayvancılığında her türde bir düșük verim gerçeğinin işareti olarak kabul edilmelidir (Anonim 2001b).

Makinayla sağımda, sağılan hayvanın yavrusunun emişinde söz konusu olan fiziksel olgular taklit edilmektedir. Oyle ki, sağım için gerekli vakum üretilerek sütün memeden alınmasında gerekli sıkıştırma-gevşeme işi için vakumun periyodik olarak kesilmesi sağlanmaktadır (Ayık 1985). Böylece kan dolaşımı artırilmakta ve meme

\footnotetext{
'Ankara Univ, Ziraat Fak. Tarım Makinları Bölümú-Ankara
} 
Çizelge 1. Çeşitli ülkelerde küçükbaş hayvan variığı ve ülkelerin payı (Anonim 1999)

\begin{tabular}{|c|c|c|c|c|}
\hline \multirow[b]{2}{*}{ Olkeler } & \multicolumn{2}{|r|}{ Koyun } & \multicolumn{2}{|r|}{ Keçi } \\
\hline & $\begin{array}{c}\text { Sayı } \\
\text { (bin baș) }\end{array}$ & Dúnya varlığındaki pay (\%) & $\begin{array}{c}\text { Sayı } \\
\text { (bin baş) }\end{array}$ & Dünya varliğındaki pay (\%) \\
\hline Afganistan & 14300 & 1,33 & 2200 & 0,31 \\
\hline Cezayir & 17700 & 1,65 & 3200 & 0.45 \\
\hline Banglades & 1158 & 0,10 & 33500 & 4,72 \\
\hline Brezilya & 18300 & 1,70 & 12600 & 1,77 \\
\hline Bulgaristan & 2774 & 0,25 & 1048 & 0,14 \\
\hline Cin & 127163 & 11,87 & 141998 & 20,03 \\
\hline Fransa & 10240 & 0,95 & 1199 & 0,16 \\
\hline Almanya & 2298 & 0,21 & 110 & 0,01 \\
\hline Yunanistan & 8756 & 0,81 & 5700 & 0,80 \\
\hline Hindistan & 57600 & 5,38 & 122530 & 17,28 \\
\hline Tran & 53000 & 4,95 & 27000 & 3,80 \\
\hline Irak & 6000 & 0,56 & 1300 & 0,18 \\
\hline Italya & 10770 & 1,00 & 1365 & 0,19 \\
\hline Pakistan & 32383 & 3,02 & 48575 & 6,85 \\
\hline Torkiye & 30238 & 2,82 & 8376 & 1,18 \\
\hline Toplam & 1070625 & 100,0 & 708885 & 100,0 \\
\hline
\end{tabular}

Çizelge 2. Türkiye'de sağılan küçükbaş hayvan sayłları ve süt ürețimi (Anonim 1998)

\begin{tabular}{|c|c|c|c|c|c|c|}
\hline \multirow{2}{*}{ Yıllar } & \multicolumn{3}{|c|}{ Sağilan hayvan sayısi (Baş) } & \multicolumn{3}{c|}{ Süt üretimi (Ton) } \\
\cline { 2 - 7 } & Koyun & Kıl keçisi & Ankara keçisi & Koyun & \multicolumn{1}{c|}{ Kı keçisi } & Ankara keçisi \\
\hline 1990 & 23698830 & 5357670 & 655330 & 1145015 & 322725 & 13810 \\
\hline 1991 & 23222330 & 5275480 & 602120 & 1127430 & 322120 & 12665 \\
\hline 1992 & 22399330 & 5082520 & 519720 & 1089230 & 308415 & 11005 \\
\hline 1993 & 21531850 & 4991460 & 472420 & 1047325 & 304120 & 9855 \\
\hline 1994 & 20507510 & 4769110 & 393410 & 991760 & 288550 & 8160 \\
\hline 1995 & 19262500 & 4544500 & 363090 & 934495 & 269670 & 7535 \\
\hline 1996 & 18890080 & 4379230 & 346650 & 921660 & 258155 & 7290 \\
\hline 1997 & 17168690 & 4111260 & 295930 & 826348 & 243044 & 6258 \\
\hline
\end{tabular}

başı üzerinde sabit basıncın acı veren etkisı önlenmiş olmaktadır (Gürhan 1997). Sağım makinalarında kullanilan nabız aygıtı, sistemin en önemli organıdır. Sağım ve masaj fazlarında kesintili vakum, bu aygit tarafından olușturulmaktadır. Elektronik nabız aygitlarında elektromanyetik bir valf düzeni ve buna komuta eden bir elektronik kontrol ünitesi bulunmaktadır (Vatandaş ve Gurhan 1998). Nabız odası vakum eğrisinde, nabız aygıtı tarafından olușturulan 4 evre bulunmaktadır. Bunlar sırasıyla; vakum artış evresi (a), en yüksek vakum evresi (b), vakum azalış evresi (c) ve en dūşük vakum evresi (d), dir. Diğer yandan a ve b evrelerinin toplamının tôm çevrim süresine oranina nabız oranı denilmektedir. Ayrıca pulsasyonun diğer bir karakteristig̈i de, dakikadaki çevrim sayısını gösteren nabız sayısı parametresidir. Nabız oranı ve nabız sayısı değerleri ülkeden älkeye farklılıklar gösterebilmektedir (Uçucu ve Yağcıoğlu 1980). Nabız aygıtlarinin yapisal ve işlevsel özellikleri üzerinde çeşitli çalışmalar yapilmıştır. Bu çalışmalann sonucunda işlevsel özellikler yönunden elektronik tip nabız aygitlarının Ustünlügü ortaya konulmuştur (Gürhan 1997).

Dünyada genel olarak kullanilan koyun sağimina uygun sağim makinalarının tümunde işletme parametreleri belirli değerler arasında değişim göstermektedir. Saĝım makinalarinda vakum seviyeleri genellikle $35-45 \mathrm{kPa}$ değerieri arasinda olmaktadir (Dawe 1997, Gilbert 1997). Temel işletrne parametrelerinden biri olan vakum seviyesi bu değerlerin alında alındığında birim zamandaki süt verimi ve sağilan hayvan sayısı azalmakta, üzerindeki değerlerde ise hayvanların meme sağlığı olumsuz olarak etkilenmekte ve memelerde travma ve mastitis gibi hastalıklar gözlenmektedir (Dawe 1997)

Koyun sağımında kullanılan sağım makinalarının dakikadaki nabız sayısı değerleri ise dänya genelinde kullanilan farklı sağım makinalarında 90-120 nabız (puls) arasında değişmektedir. Farklı ùlkelerde sağımı yapılan farklı koyun ırkłarı için bu değerler sağım makinalarında farkı oranlarda alınmaktadır. Dakikadaki nabız sayısi; Fransada kullanılan sağım makinalarında 120 nabız/dak. Avustralya da kultanilanlarda ise 90 nabiz/dak. olarak alınmaktadir (Dawe 1997, Gilbert 1997, Langford and Gilbert 1997), Koyun ve keçi sağımında kullanılan sağım makinalarinin önemil işletme parametrelerinden biri olan nabız oranı değerleri ise genel olarak $70: 30$ ile $60: 40$ değerleri arasında değişen oranlarda uygulanabilmektedir (Gilbert 1997).

Dünyada çeșitli ırk keçiler üzerinde, vakum seviyesi, nabız oranı ve sayısının, sağım performansı ve meme sağlığı üzerine etkilerinin incelendiḡi değişık araștırmalar yapilmıştı. Keçilerin sağılması için kullanilacak sağım makinasının sahíp olması gereken uygun parametrelerin ne olması gerektiğini ortaya koyan bu araștırmalar sonunda elde edilen veriler; nabız sayısı deg̈erindeki artışın sağım süresini azalttığıni ortaya koymakta ve keçilerin sağımında kullanılacak süt sağım makinasını $60: 40$ nabız orani, 90 nabız/dak. nabız sayısı ve 45.52 vakum seviyes değerlerine sahip olmasi gerektiğinl göstermektedir. 
Elektronik tip nabız aygıtlannin pulsasyon sistemindeki vakum değişimlerinden etkilenmemeleri en önemli ústünlókleridir. Bu sayede çevrim evreleri (a,b,c ve d) yüksek bir kararlilıkla gerçekleștirilebilmektedir. Uygulamada karşılaşılan elektronik nabız aygıtları sabit bir pulsasyon karakteristiği göstermektedir. Bu aygıtların programlanabilir nitelikte olanlarına ilişkin deneysel çalı̧̧malar literatürde mevcut olup (Cant ve Reitsma 1979) henöz uygulamada yaygınlaşmamıştır.

Programlanabilir özellikteki bir nabız aygıtı, nabız oranı ve nabız sayısı gibi pulsasyon karakteristiklerinin kolayca değiştíilebilmesine olanak sağlayacağından uygulamadan gelen isteklere rahatlikla cevap verebilecektir (Hamann ve Tolle 1980).

Olkemiz küçükbaș hayvan sağımına uygun parametrelere ve yapıya sahip bir merkezi kontrol ünitesinin geliştirilmesi, bu alandaki süt üretiminin ve sôt ürünlerinin nitelik ve niceliklerinin artmasını sağlayacaktır.

\section{Materyal ve Yöntem}

Bu çalışmada alkemizdeki koyun ve keçilerin sağımında kullanılabilecek sağım makinasının vakum seviyesi, vakum hava debisi, nabız sayısı, nabız orani gibi temel parametrelerin değişik seviyelerinde ve oranlarında Ankara Universitesi Ziraat Fakültesi Tarım Makinaları Anabilim Dali laboratuarlarında yapilmıștir. Temel parametrelerin ölçümünde, standartlara uygun ölçümleri sağlayan temel cihaz olarak; "Alfatronik Tester MK IV" dijital-yazıcılı ölçme cihazi kuilanilmiştir. Deneylerde, pulsotest (yazıcili) nabız-vakum ölçme cihazı lle nabız ve vakum değerleri, uluslararası ve TSE sağım makinası test standartlarina uygun olarak belirlenmiștir.

Geliştirilen elektronik kontrol ünitesi ise bir PIC (Peripheral Interface Controller) ve buna bağlı olarak çalışan bir RC osilatơrü ile gọç kaynağından oluşmaktadır. Nabız evrelerine ait sinyaller PIC'e yuklenmiş proğram tarafindan üretilerek RBO ve RB1 çıkışlarından alınmıs, elektronik valfin S1 ve S2 selenoidlerine uygulanmıştır. Bu yolla sağım makinası vakum pompasından gelen vakum, her íki sağım başlığına $(1,2)$ periyodik olarak verilmiştir (Şekil 1).

PIC, programlanabilir bir kontrol aygitıdır. Belleğine yâklenmiş olan programi bir RC osilatörünün belirlediği hızda, gúç kaynağından aldığı enerjiyle yürütür. Giriş ve çıkış terminalleri farklı amaçlar için programlanabilir, $\mathrm{Bu}$ yolla çok az diş devre elemanı yardımıyla çeşitli komuta işlemlerini başarıyla gerçekleştirebilir.

Çalışmada 16F84 tipi bir PIC ve bu aygıtı programlayabilmek için bir PIC programlayıcı kullanilmıştır. Geliştirilen yazılımlar PIC BASIC diliyle yazılmış, daha sonra HEX tipi kütüğe dönūştürülmüştür.

Geliştirilen nabız kontrol ùnitesi, bir transformatörle şebeke lizerinden beslenmekte olup, kontrol devresinde 5 VDC gerilime gereksinim duymaktadir. Elektromanyetik valf selenoidleri ise 24 VDC gerilimle çalışmaktadir. Seyyar tip tek sağım ünitell güğomla bir sağım makinasına

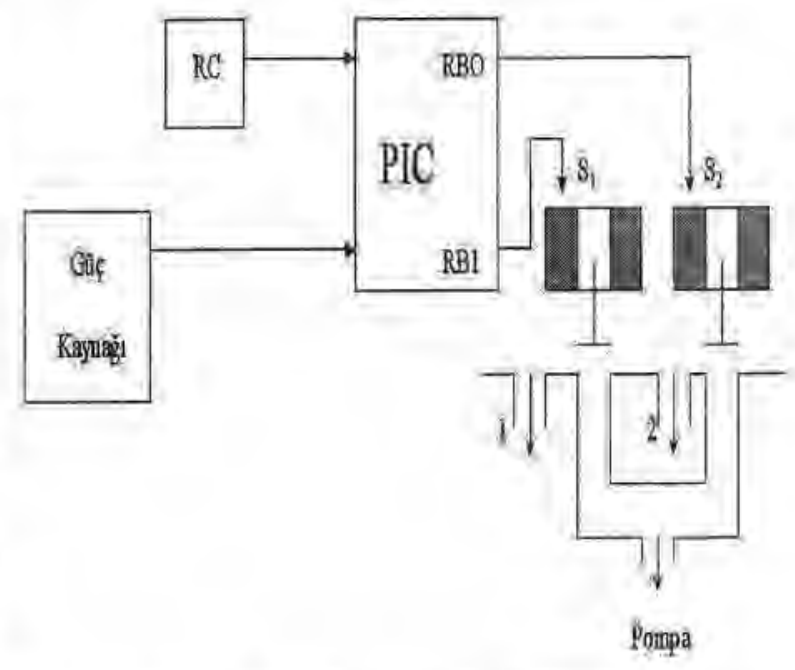

Şekil 1. Nabiz kontrol diyagrami (Gurhan ve Vatandas 2001)

bağlanan nabız aygitının performans değerleri Alfa Laval MK IV test clihazıyla ölçülmüştür. Olçümlerde farklı nabız oranları, nabız frekanslari ve vakum basıncı değerler kullanılmıştır.

Denemeler, küçükbaş hayvanlarin tưmünùn sağımında kullanılan saĝım makinalarına ait nabız aygıtı parametrelerinin simir değerleri olan oç farklı vakum seviyesinde $(35,40$ ve $45 \mathrm{kPa}$ ) ve üç farklı nabız sayis $\left(90,105\right.$ ve $120 \mathrm{~min}^{-1}$ ) kademesinde gerçekleştirilmiştir. Çalışma vakumunun farklı seviyeleri denemenin yapıldığ sağım makinası üzerinde ayarlanarak elde edilmiștir Denemenin yapıldığı aç farklı nabız sayısı kademesinin elde edilmesinde ise merkezi nabız kontrol ünitesinin PIC devresine aktarmak azere geliştirilen üç farklı nabız kontrol programı kullanilmıştır (Şekil 2). Tasarımı yapilan PIC tabanlı nabız kontrol únitesi istenilen nabız degerleri yanında her bir nabız seviyesi değeri için \%70-30 nabız oranıni da gerçekleştirecektir. Microkontrolörle gerekli olan bu bilgiler kendisine ait bir yazılım ve programlama kart yardımıyla aktarilmıştır. Çalıșmada, alkemizde yetiştirilen küçäkbaş hayvanların sağimina uygun parametrelere ve yapıya sahip bir kontrol ünitesinin PIC tabanlı olarak gerçekleştirilmesi amaçlanmıştır.

\section{Bulgular ve Tartişma}

Geliștíilen nabız kontrol unitesi ve elektromanyetik valften oluşan nabız aygıtinin performansına ait değerler Çizelge 3, Çizelge 4 ve 5 ' de görülmektedir. Çizelgeler de yer alan veriler nominal nabız oranı değerlerine göre elde edilmiştir. Buna göre deneyler sonucunda belirlenen performansa ilişkin şu değerlendirmeler yapılabilmektedir.

1. Nabız sayısı vakum basıncından etkilenmemektedir. Kullanilan her oc vakum basınci dozeyinde $(35,40,45$ $\mathrm{kPa}$ ), nabız frekansları programlandığı deg̈erde sabit tutulabilmiştir.

2. Nabız oranları vakum basıncından bağımsız olarak elde 

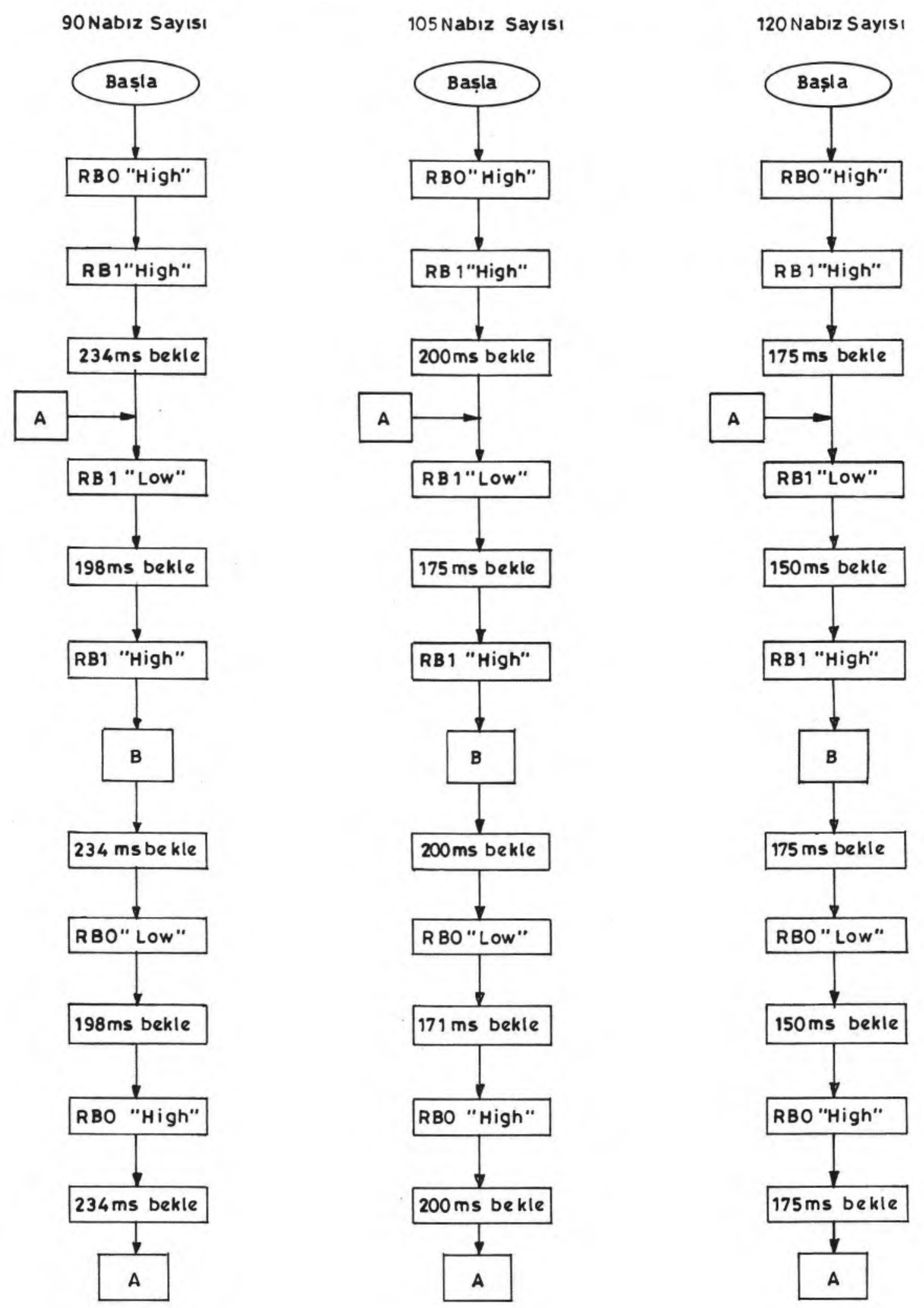

Şekil 2. Farklı nabız sayılarına ilişkin nabız kontrol programlarına ait akış diyagramları (Gürhan ve Vatandaş 2001) 
edilmiştir. Nabız oranındaki nominal değerlere göre en büyük sapma $\% 0,9$ olarak ölçŭlmüştür.

3. Kullanılan Alfatronik Tester MK IV cihazı yardımıyla her nabız sayısı değerlerindeki 35,40 ve $45 \mathrm{kPa}$ 'lık sistem vakumu seviyeleri için nabız aygıtının kanalında oluşan nabız evrelerine ait değerler elde edilmiştir. Çizelge değerlerinden de izlenebileceği gibi kullanilan merkezi kontrol ünitesi (PIC) yüksek bir kararlılık göstermiștir. Bir nabız periyodunda sütün sağıldığı ve en yüksek vakum evresi olan gevşeme fazı (b) oranının \%30'dan, meme başının sıkıldığı en düşük vakum evresi olan masaj fazının da (d) \%15' den az olmaması istenmektedir (Anonymous 1977,1983). Cizelgelerde yer alan.bu değerlerin belirtilen sınır koşullarına uygun olduğu görülmüștür.

4. Nabız eğrileri eş zamanlı hareket sağlayan pulsasyona uygundur.

\section{Sonuç}

1.Geliştirilen merkezi kontrol ünitesiyle gerçekleștirilen nabız denetimi sistem vakumundaki dalgalanmalardan etkilenmemektedir.

2. Nabız eğrisinin $a, b, c$ ve d karakteristikleri yüksek bir kararlılıkla elde edilmiştir.

3. Tüm nabız parametreleri uluslararası standartlarda verilen değerlere uygundur.

4. Sistemde nabız karakteristikleri bir yazılımla elde edildiğinden, esnek bir özelliğe sahiptir ve farklı sağım koşullarına kolaylıkla uyumlu hale getirilebilir.

5. Gerçekleștirilen sistemin en önemli sakıncası az sayıda sağım başlığına sahip makina ve tesisler için ilk yatırım maliyetinin yüksek olmasıdır.

Çizelge $3.90 \mathrm{~min}^{-1}$ nabız sayısı değerinde farklı vakum seviyelerinde nabız aygıtının kanalında oluşan nabız evreleri

\begin{tabular}{|c|c|c|c|c|c|c|c|c|c|c|c|c|}
\hline \multirow{3}{*}{$\begin{array}{l}\text { Vakum } \\
\text { seviyeleri } \\
\text { (kPa) }\end{array}$} & \multicolumn{12}{|c|}{ Nabız evreleri } \\
\hline & \multicolumn{2}{|c|}{$a+b$} & \multicolumn{2}{|c|}{$c+d$} & \multicolumn{2}{|c|}{ A } & \multicolumn{2}{|c|}{ b } & \multicolumn{2}{|c|}{ c } & \multicolumn{2}{|c|}{ d } \\
\hline & $\%$ & $\mathrm{~ms}$ & $\%$ & $\mathrm{~ms}$ & $\%$ & Ms & $\%$ & $\mathrm{~ms}$ & $\%$ & $\mathrm{~ms}$ & $\%$ & $\mathrm{~ms}$ \\
\hline 35 & 70,8 & 450 & 29,2 & 186 & 13,7 & 87 & 57,1 & 363 & 10,2 & 65 & 19,0 & 121 \\
\hline 40 & 70,4 & 448 & 29,6 & 188 & 14,9 & 95 & 55,5 & 353 & 10,7 & 68 & 18,9 & 120 \\
\hline 45 & 70,1 & 446 & 29,9 & 190 & 16,5 & 105 & 53,6 & 341 & 10,4 & 66 & 19,5 & 124 \\
\hline
\end{tabular}

Çizelge 4. $105 \mathrm{~min}^{-1}$ nabız sayısı değerinde farklı vakum seviyelerinde nabız aygıtının kanalında oluşan nabız evreleri

\begin{tabular}{|c|c|c|c|c|c|c|c|c|c|c|c|c|}
\hline \multirow{3}{*}{$\begin{array}{l}\text { Vakum } \\
\text { seviyeleri } \\
(\mathrm{kPa})\end{array}$} & \multicolumn{12}{|c|}{. Nabız evreleri } \\
\hline & \multicolumn{2}{|c|}{$a+b$} & \multicolumn{2}{|c|}{$c+d$} & \multicolumn{2}{|c|}{ A } & \multicolumn{2}{|c|}{ b } & \multicolumn{2}{|c|}{ c } & \multicolumn{2}{|c|}{ d } \\
\hline & $\%$ & $\mathrm{~ms}$ & $\%$ & $\mathrm{~ms}$ & $\%$ & Ms & $\%$ & $\mathrm{~ms}$ & $\%$ & $\mathrm{~ms}$ & $\%$ & $\mathrm{~ms}$ \\
\hline 35 & 70,8 & 384 & 29,2 & 158 & 15,7 & 85 & 55,2 & 299 & 10,7 & 58 & 18,5 & 100 \\
\hline 40 & 70,8 & 385 & 29,2 & 159 & 16,5 & 90 & 54,2 & 295 & 10,6 & 58 & 18,6 & 101 \\
\hline 45 & 70,4 & 382 & 29,6 & 161 & 20,1 & 109 & 50,3 & 273 & 10,2 & 56 & 19,4 & 105 \\
\hline
\end{tabular}

Çizelge 5. $120 \mathrm{~min}^{-1}$ nabız sayısı değerinde farklı vakum seviyelerinde nabız aygıının kanalında oluşan

\begin{tabular}{|c|c|c|c|c|c|c|c|c|c|c|c|c|}
\hline \multirow{3}{*}{$\begin{array}{l}\text { Vakum } \\
\text { seviyeleri } \\
\text { (KPa) }\end{array}$} & \multicolumn{12}{|c|}{ Nabız evreleri } \\
\hline & \multicolumn{2}{|c|}{$a+b$} & \multicolumn{2}{|c|}{$c+d$} & \multicolumn{2}{|c|}{ A } & \multicolumn{2}{|c|}{ b } & \multicolumn{2}{|c|}{ c } & \multicolumn{2}{|c|}{ d } \\
\hline & $\%$ & $\mathrm{~ms}$ & $\%$ & $\mathrm{~ms}$ & $\%$ & Ms & $\%$ & $\mathrm{~ms}$ & $\%$ & $\mathrm{~ms}$ & $\%$ & $\mathrm{~ms}$ \\
\hline 35 & 70,8 & 332 & 29,2 & 137 & 18,1 & 85 & 52,7 & 247 & 10,9 & 51 & 18,3 & 86 \\
\hline 40 & 70,9 & 332 & 29,1 & 136 & 21,4 & 100 & 49,6 & 232 & 11,1 & 52 & 18,0 & 84 \\
\hline 45 & 70,8 & 328 & 29,2 & 135 & 21,3 & 99 & 49,5 & 229 & 10,6 & 49 & 18,6 & 86 \\
\hline
\end{tabular}




\section{Kaynaklar}

Anonim, 1998. Devlet Istatistik Enstitüsü Yayınları, Ankara.

Anonim, 1999, Agricultural Istatistics. http://apps.fao.org

Anonim, 2001a. Dünya'da Avrupa Birliği'nde ve Türkiye'de Hayvansal Üretim ve Ticareti. Çamlıca Kültür ve Yardım Vakfı Yayınları. Istanbul.

Anonim, 2001b. Hayvancılık. Sekizinci Beş Yıllık Kalkınma Planı, Özel Ihtisas Komisyonu Raporu. Ankara.

Anonymous,1977. Milking Machine Installations-Vocabulary (ISO 3918). International Standart.

Anonymous, 1983. Milking Machines Installations-Construction and Performance. ISO (International Standart) 5707.

Ayık, M. 1985. Hayvancılıkta Mekanizasyon. Ankara Üniv. Ziraat Fak. Yayınları:950 Ders Kitabı:273, Ankara.

Cant, E. J. and S. Y. Reitsma, 1979. A programmable pulsator control unit for milking systems. J. Agric. Engng. Res., 24, 331-336.

Dawe, S. T. 1997. Sheep Dairy Parlours. Agricultural Institute Yanco NSW 2703, Australia.

Gilbert, C. 1997. Principles of Machine Milking of Dairy Sheep, Finley, Australia.

Gürhan, R. 1997. Pulsatörlerin işlevsel karakteristiklerinin belirlenmesi üzerine karşılaşıırmalı bir araştırma. Tr. J. of Agric. and For., 21, 29-34.
Gürhan, R. ve M. Vatandaş, 2001. Sağım makinalarına uygun programlanabilir bir nabız aygıtı kontrol ünitesi geliștirilmesi. Ankara Üniv. Ziraat Fak. Tarım Bilimleri Dergisi, 7 (3) 48-53.

Hamman, J. and A. Tolle, 1980. Comparison between manual and mechanical stimulation. Milchwissenschaft, 35 (5) 271-273.

Langford, C. M. and G. Gilbert, 1997. Flock Records for Sheep Dairying. Sheep Dairying. Finley, Australia.

Muldowney, C. J. and J. R. O'Callaghan, 1970. The Interactions of components on the vacuum stability milking machines. J. of Agriculture Engineering Research, 15 (4) 331-346.

Uçucu, R. ve A. K. Yağcıoğlu, 1980. Yapısal ve ışlevsel yönden süt sağım makinalarında aranılan özellikler. Ege Üniv. Ziraat Fak. Tarımsal Mekanizasyon Semineri -5., Izmir.

Vatandaş, M. ve R. Gürhan, 1998. Sağım makinalarına uygun bir elektronik pulsatör geliştirilmesi. Ankara Üniv. Ziraat Fak. Tarım Bilimleri Dergisi, 4 (2) 49-51.

Iletişim adresi:

Recai GÜRHAN

Ankara Öniv. Ziraat Fakültesi, Tarım Makinaları Bölümü-Ankara

Tel: 031231705 50/1601

Fax: 03123183888

E-mail: rgurhan@hotmail.com.tr 